\begin{tabular}{ccc}
\hline & International Journal of Engineering \& Technology, 7 (2.33) (2018) 324-328 \\
SPC & Website www.sciencepubco.com/index.php/IJET \\
Research paper & Technology \\
\hline
\end{tabular}

\title{
A study on the sandwich-style notched tensile specimens for different materials through a simulation analysis
}

\author{
Jung-Ho Lee ${ }^{1}$, Jae-Ung Cho ${ }^{2 *}$ \\ ${ }^{1}$ Department of Mechanical Engineering, Graduate School, Kongju National University, 1223-24, Cheonan Daero, Seobuk- \\ Gu, Cheonan-Si Chungnam,31080, Korea \\ ${ }^{2}$ Division of Mechanical \& Automotive Engineering, Kongju National University, 1223-24, Cheonan Daero, Seobuk-gu, Cheonan- \\ Si Chungnam, 31080, Korea \\ *Corresponding author E-mail: jucho@kongju.ac.kr
}

\begin{abstract}
Background/Objectives: This study designed a model that used the sandwich-style notched tensile specimens of the same specifications by applying to the properties of CFRP, stainless steel, and aluminum, and performed a test simulation.

Methods/Statistical analysis: The study used CATIA design software to perform the 3D modeling of the sandwich-style notched tensile specimens with the properties of CFRP, a composite material, and stainless steel and aluminum, both ordinary metals, and then, performed a tensile test simulation.

Findings: By designing the sandwich-style notched tensile specimens of the same specifications and performing a test simulation, we were able to verify the tensile strength and durability of the specimens for the different materials. This study result showed that unlike the specimens for the ordinary metals, those specimens with the properties of the composite material of CFRP first showed maximum load instead of breaking immediately due to the fibers in CFRP, before they resisted displacement in response to the alternately increasing and decreasing load until it fractured. To be specific, we saw that the CFRP specimens had the more excellent tensile strength and durability. Improvements/Applications: The data obtained from the studies will serve as the basic data for studies on the composite materials like CFRP and other various materials.
\end{abstract}

Keywords: Notched Tensile Specimen; Material; Mechanical Characteristic; Maximum Load; Durability.

\section{Introduction}

Today, materials meet a gradually widening variety of uses such as machines, mechanical structures, automobiles, and ships. At the same time, types of materials are diversifying, which include single-metal materials, light-weight composite materials which focus on lightness, and heterogeneous materials that are made of materials with varied properties. Lately, composite materials, which are both durable and light, are actively researched and developed. Among all of them, CFRP (Carbon fiber reinforced plastic), a composite material that draws attention for its durability and lightness, is lighter and shows the tensile strength greater than ordinary metals[1-5]. In this study, for which we took notice of the composite material of CFRP, we compared and analyzed tensile strength and durability, performed a simulation analysis by designing sandwich-style notched tensile specimens that applied to the properties of CFRP, stainless steel, and aluminum, and verified the tensile strength and durability of the specimens for the different materials. Thus, the study is concerned with tensile strength with the properties of CFRP, a composite material that draws attention for its excellent durability and lightness, and stainless steel and aluminum, the widely used metals, and is designed to acquire the data for future researches on the fracture characteristics and durability of heterogeneous materials and various composite materials. We believe that the data obtained from the specific researches will serve as the basic data for researches on composite materials like CFRP and other different materials[6-10].

\section{Research method and models}

In this study, we used CATIA design program to perform the 3D modeling of sandwich-style notched tensile specimens applied to the properties of CFRP, a composite material, and stainless steel and aluminum, both ordinary metals, and then, performed a tensile test analysis. Figure 1 shows the specifications of tensile specimens, which are identical as seen in the figure. The specimens are $15 \mathrm{~mm}$ wide and $80 \mathrm{~mm}$ long. The width of the plate is $0.5 \mathrm{~mm}$ and that of the core is $1 \mathrm{~mm}$. The notches are $2 \mathrm{~mm}$ wide and $1 \mathrm{~mm}$ long. In this study, we wanted to study the tensile strength of such sandwich-style notched tensile specimens. Additionally, Table 1 and 2 shows the properties that are applied to the different sandwich-style notched tensile specimens to perform a simulation analysis [11-12]. 

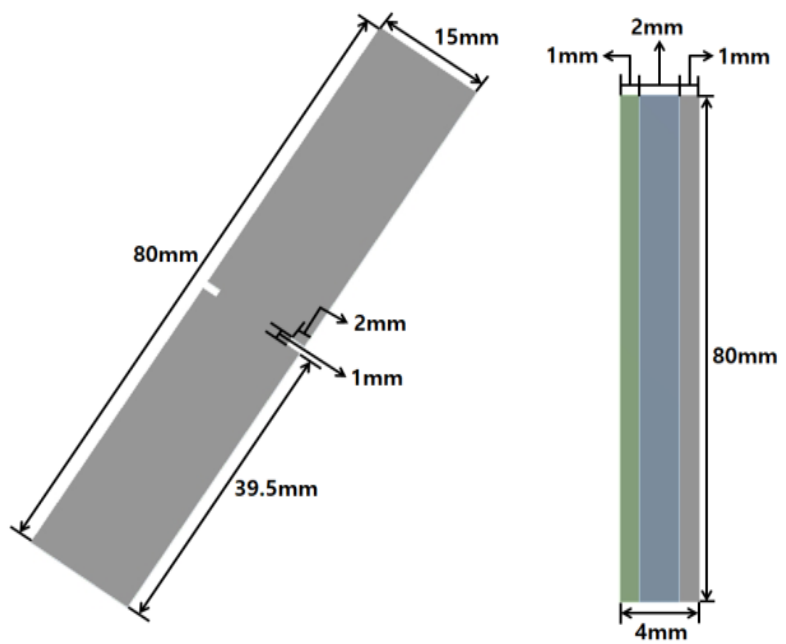

Fig. 1: Dimensions of Notched Tensile Specimen.

Table 1: Material Properties (Stainless Steel and Aluminum)

\begin{tabular}{lll}
\hline Material & Stainless steel & Aluminum \\
\hline Density(kg/m3) & 7750 & 2770 \\
Young's Modulus(GPa) & 193 & 71 \\
Poisson's Ratio & 0.31 & 0.33 \\
Yield strength(MPa) & 207 & 280 \\
Ultimate strength(MPa) & 586 & 310 \\
\hline
\end{tabular}

Table 2: Material Properties (CFRP)

\begin{tabular}{ll}
\multicolumn{2}{c}{ Table 2: Material Properties (CFRP) } \\
\hline Material & CFRP \\
\hline Density & $1.57 \mathrm{~kg} / \mathrm{m} 3$ \\
Poisson's Ratio(v12) & 0.3 \\
Poisson's Ratio(v23) & 0.74 \\
Tensile Modulus(E1) & $132 \mathrm{GPa}$ \\
Tensile Modulus(E2) & $8.98 \mathrm{GPa}$ \\
Tensile Strength(Xt) & $1447 \mathrm{MPa}$ \\
Tensile Strength(Yt) & $51.72 \mathrm{MPa}$ \\
Compressive Strength(Xc) & $1447 \mathrm{MPa}$ \\
Compressive Strength(Yc) & $206.2 \mathrm{MPa}$ \\
\hline
\end{tabular}

\section{Boundary conditions}

Figure 2 shows the boundary conditions that were applied to the different sandwich-style notched tensile specimen models to perform a tensile test simulation. Here, the boundary conditions applied to the specimens are identical and are all assumed to be installed on the tensile tester. First, assuming that a specimen is fixed in the lower load cell of the tensile tester, we applied a fixed support to the bottom end of the specimen. Also assuming that the specimens were being applied by the upper load cell, we performed the experiment by applying force-displacement of $5 \mathrm{~mm} / \mathrm{min}$ to the top end of the specimen [13-14].

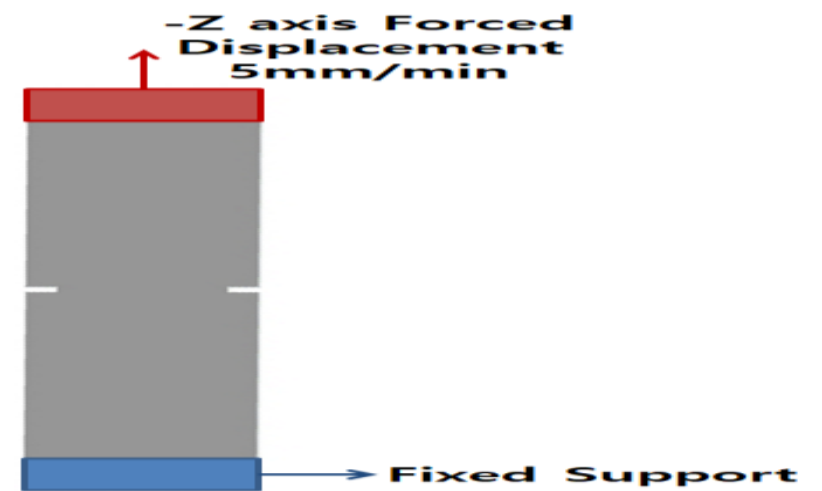

Fig. 2: Boundary Conditions of Tensile Specimen Models.

\section{Simulation analysis results}

Figure 3 shows in a graph the resulting load values as affected by displacement, which occurred when we performed the simulation analysis on the CFRP-stainless steel core sandwich-style notched tensile specimen model. The analysis showed that with the loaddisplacement in progress, the load that occurred in the specimen model tended to increase gradually, with the load sharply increasing until the load-displacement reached about $4 \mathrm{~mm}$ and slowly increasing until the load-displacement reached about $7 \mathrm{~mm}$. It further showed that when the load-displacement reached about $7 \mathrm{~mm}$, the specimen incurred a maximum load of about $65,000 \mathrm{~N}$, and that after the maximum load occurred, the specimen began to fracture, with the load that applied to the specimen model decreasing gradually. However, we saw that owing to the fibers in CFRP, the load alternately increased and decreased. Figure 4 and Figure 5 showed that the maximum deformation and the maximum stress occurring in the CFRP-stainless steel core sandwich-style notched tensile specimen model were $0.0136 \mathrm{~mm}$ and $77.31 \mathrm{MPa}$, respectively.

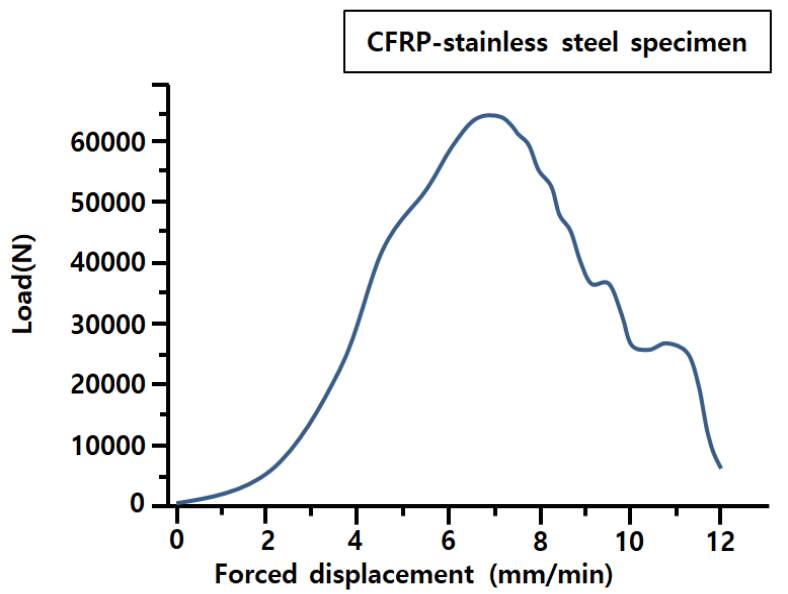

Fig. 3: Graph of Load Due to Forced Displacement at Tensile Analysis (CFRP-Stainless Steel Core Notched Tensile Specimen Model).

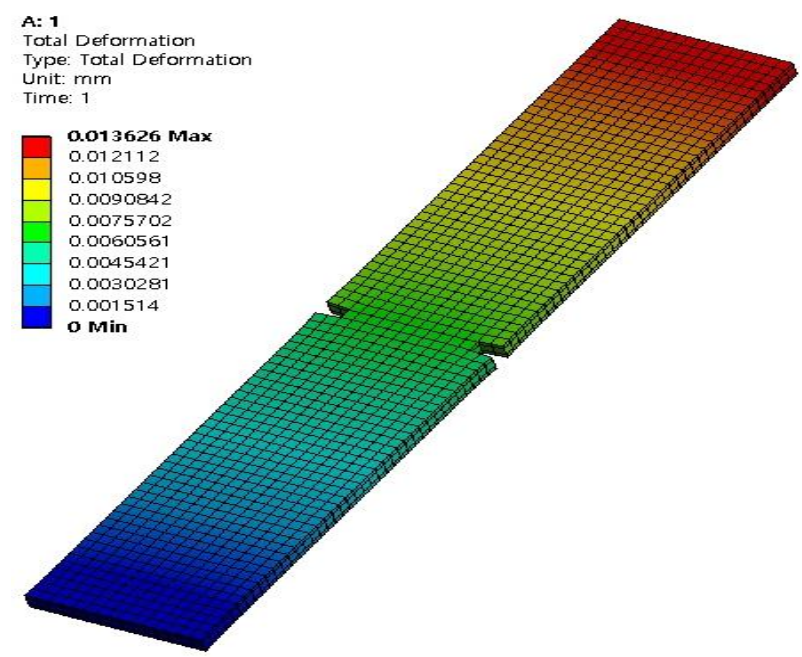

Fig. 4: Total Deformation of CFRP-Stainless Steel Core Notched Tensile Specimen Model. 


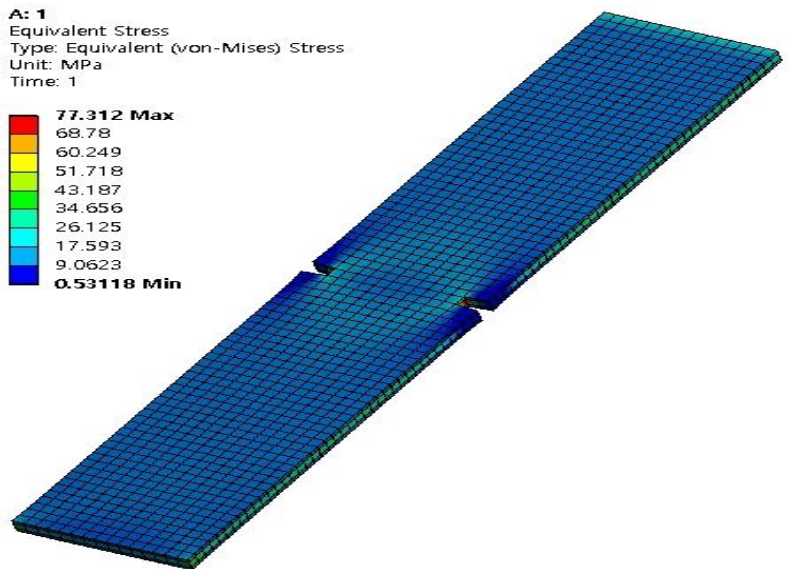

Fig. 5: Equivalent Stress of CFRP-Stainless Steel Core Notched Tensile Specimen Model.

Figure 6 shows in a graph the resulting load values as affected by displacement applied on the CFRP-stainless steel core sandwichstyle notched tensile specimen model. The simulation analysis showed again that with the load-displacement in progress, the load that occurred in the specimen model tended to increase gradually, with the load sharply increasing until the load-displacement reached about $5 \mathrm{~mm}$ and slowly increasing until the loaddisplacement reached about $6 \mathrm{~mm}$. It further showed that when the load-displacement reached about $6 \mathrm{~mm}$, the specimen incurred a maximum load of about $80,000 \mathrm{~N}$, and that from the point of the maximum load, the specimen began to fracture, with the load that applied to the specimen model decreasing gradually. However, we saw that owing to the fibers in CFRP, the load also alternately increased and decreased. Figure 7 and Figure 8 showed that the maximum deformation and the maximum stress occurring in the CFRP-aluminum core sandwich-style notched tensile specimen model were $0.0168 \mathrm{~mm}$ and $95.15 \mathrm{MPa}$, respectively.

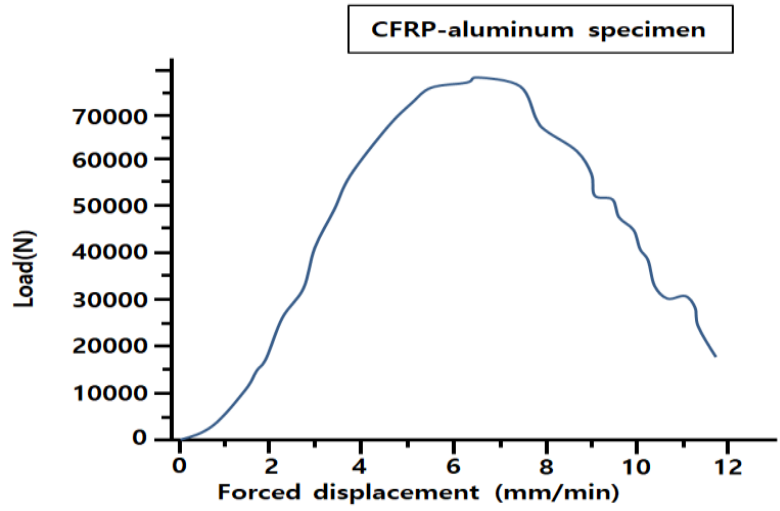

Fig. 6: Graph of Load Due to Forced Displacement at Tensile Analysis (CFRP-Aluminum Core Notched Tensile Specimen Model).

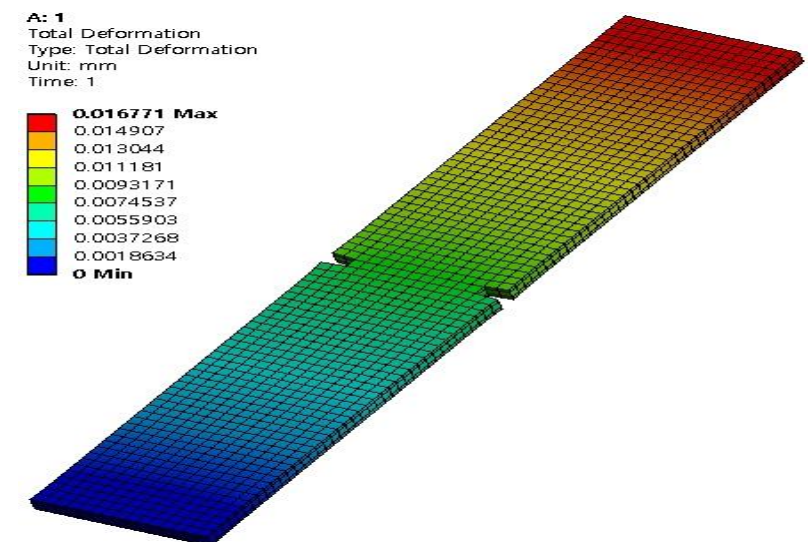

Fig. 7: Total Deformation of CFRP-Aluminum Core Notched Tensile Specimen Model.

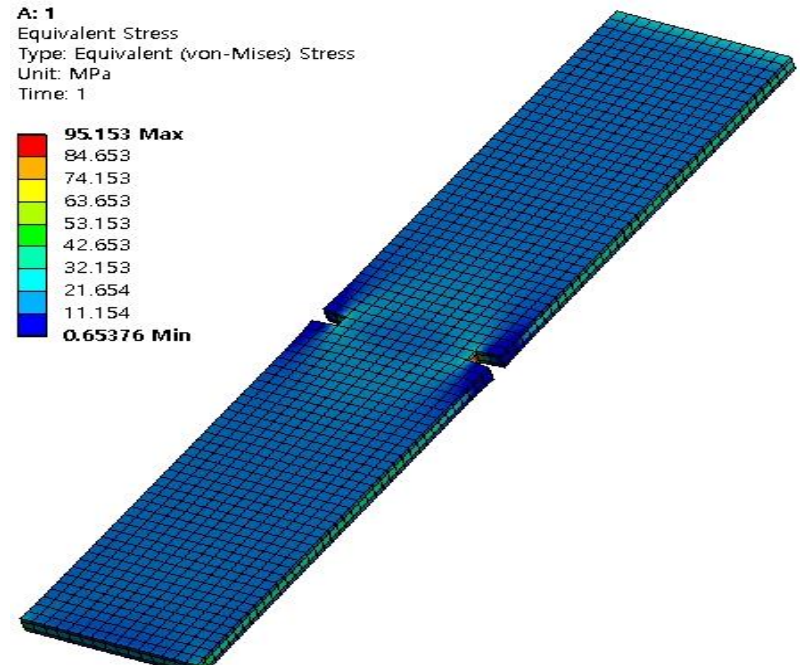

Fig. 8: Equivalent Stress of CFRP-Aluminum Core Notched Tensile Specimen Model.

Figure 9 shows in a graph the resulting load values as affected by the displacement applied on the aluminum-stainless steel core sandwich-style notched tensile specimen model. The simulation analysis showed that with the load-displacement in progress, the load that occurred in the specimen model tended to increase gradually, with the load sharply increasing until the load-displacement reached about $4 \mathrm{~mm}$ and slowly along a gentle curve until the loaddisplacement reached about $5 \mathrm{~mm}$. It further showed that when the load-displacement reached about $5 \mathrm{~mm}$, the specimen model incurred a maximum load of about $100,000 \mathrm{~N}$, and that after the maximum load occurred, the specimen model began to fracture, with the load that applied to the specimen model decreasing gradually. Figure 10 and Figure 11 showed the deformation and the stress occurring in the aluminum-stainless steel core sandwichstyle notched tensile specimen model, with the maximum deformation being $0.021 \mathrm{~mm}$ and the maximum stress being $118.94 \mathrm{MPa}$, respectively.

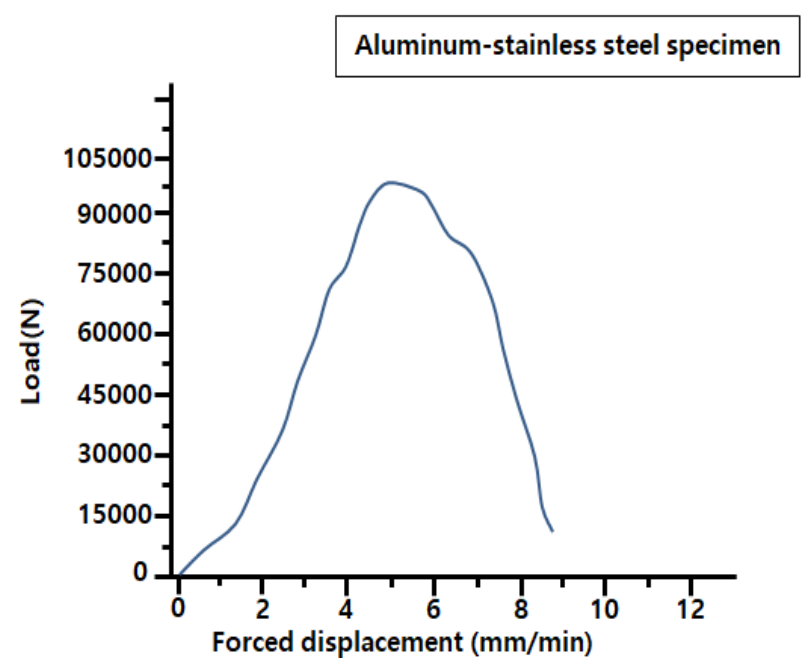

Fig. 9:.Graph of Load Due to Forced Displacement at Tensile Analysis (Aluminum-Stainless Steel Core Notched Tensile Specimen Model). 


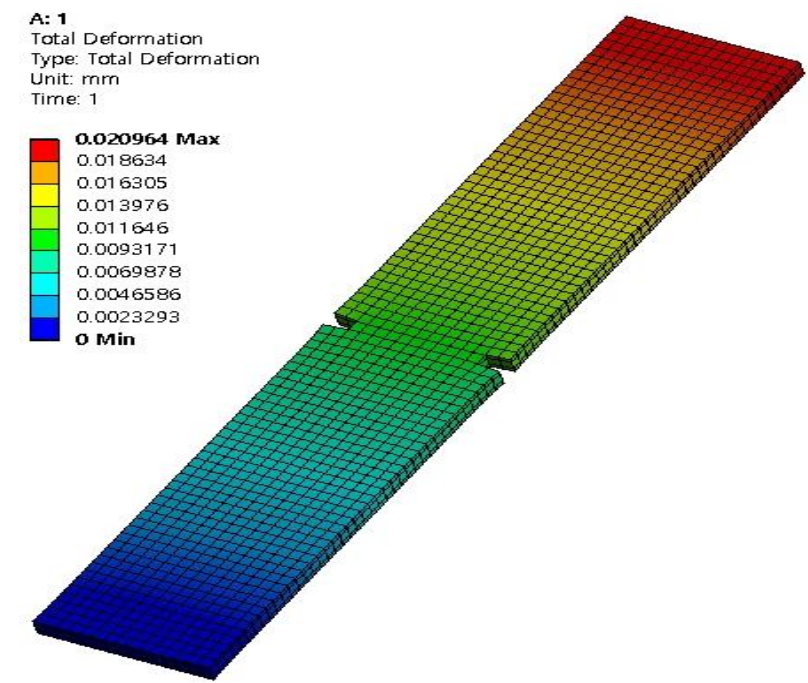

Fig. 10:.Total Deformation of Aluminum-Stainless Steel Core Notched Tensile Specimen Model.

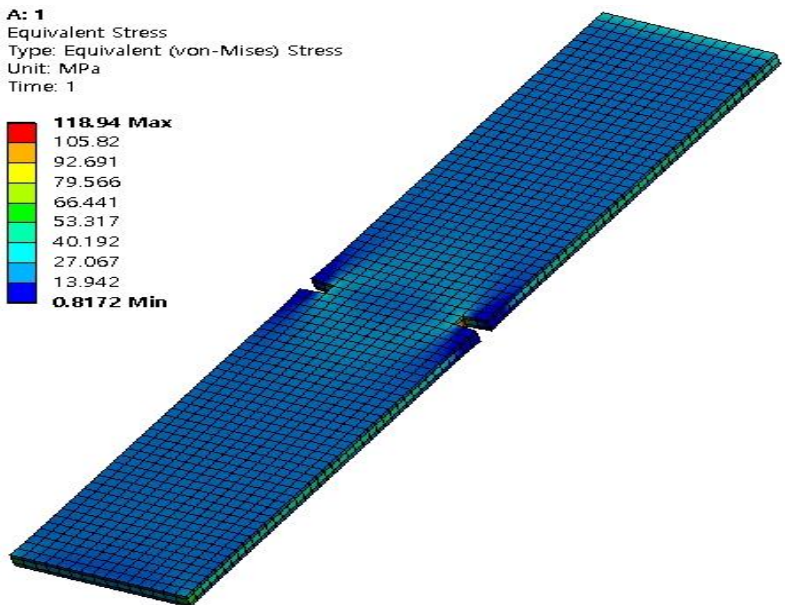

Fig. 11:.Equivalent Stress of Aluminum-Stainless Steel Core Notched Tensile Specimen Model.

Fig. 12 shows in a graph the resulting load values as affected by the displacement applied on the stainless steel-aluminum core sandwich-style notched tensile specimen model. The simulation analysis showed again that with the load-displacement in progress, the load that occurred in the specimen model tended to increase gradually, with the load sharply increasing until the loaddisplacement reached about $4 \mathrm{~mm}$ and slowly increasing until the load-displacement reached about $5 \mathrm{~mm}$. It further showed that when the load-displacement reached about $5 \mathrm{~mm}$, the specimen model incurred a maximum load of about $115,000 \mathrm{~N}$, and that after the maximum load occurred, the specimen model began to fracture, with the load that applied to the specimen model decreasing gradually. Fig. 13 and Fig. 14 showed the deformation and the stress occurring in the stainless steel-aluminum core sandwichstyle notched tensile specimen model, with the maximum deformation being $0.024 \mathrm{~mm}$ and the maximum stress being $136.78 \mathrm{MPa}$, respectively.

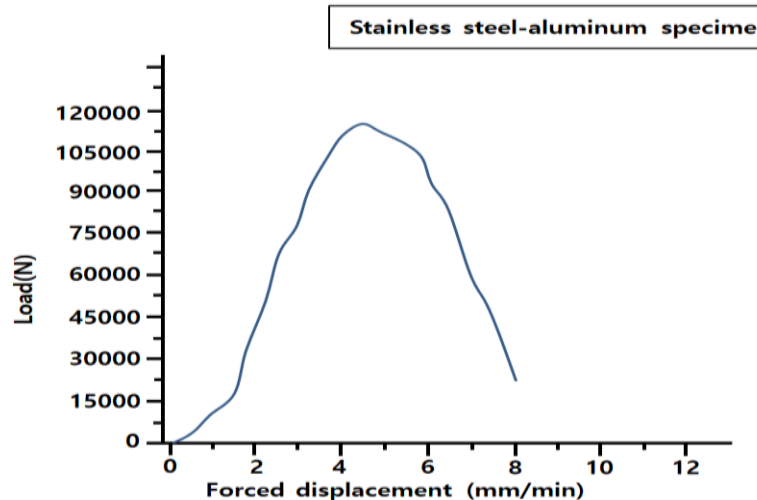

Fig. 12:.Graph of Load Due to Forced Displacement at Tensile Analysis (Stainless Steel-Aluminum Core Notched Tensile Specimen Model).

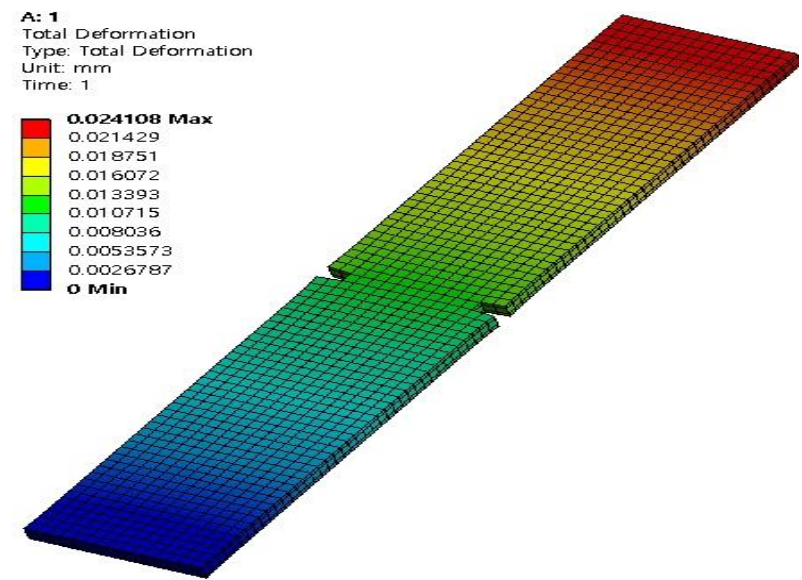

Fig. 13:.Total Deformation of Stainless Steel-Aluminum Core Notched Tensile Specimen Model.

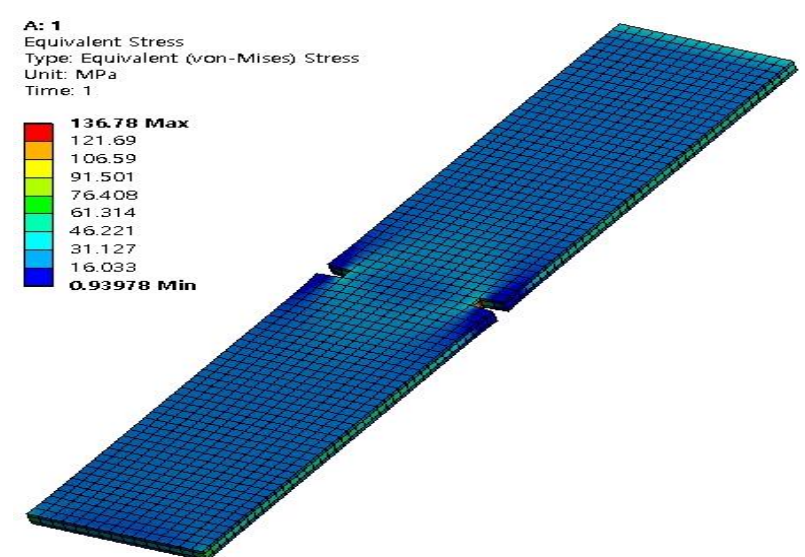

Fig. 14:.Equivalent Stress Ofstainless Steel-Aluminum Core Notched Tensile Specimen Model.

\section{Comparison of analysis results and discus- sion}

Table3 shows specific comparison results of simulation analyses of the different sandwich-style notched tensile specimen models. To compare the different specimen models, CFRP-stainless steel core sandwich-style notched tensile specimen model showed the maximum load of about $65,000 \mathrm{~N}$ when the displacement reached about $7 \mathrm{~mm}$, and CFRP-aluminum core sandwich-style notched tensile specimen model registered the maximum load of about $80,000 \mathrm{~N}$ when the displacement reached about $6 \mathrm{~mm}$. Moreover, we saw that aluminum-stainless steel core sandwich-style notched tensile specimen model showed the maximum load of about $100,000 \mathrm{~N}$ when the displacement reached about $5 \mathrm{~mm}$, and stainless steel-aluminum core sandwich-style notched tensile specimen model showed the maximum load of about $115,000 \mathrm{~N}$ when the displacement reached about $5 \mathrm{~mm}$. Meanwhile, the deformation 
and the stress for CFRP-stainless steel core sandwich-style notched tensile specimen model were about $0.0136 \mathrm{~mm}$ and about 77.31MPa and the deformation and the stress for CFRP-aluminum core sandwich-style notched tensile specimen model were about $0.0168 \mathrm{~mm}$ and about $95.15 \mathrm{MPa}$, while the deformation and the stress for aluminum-stainless steel core sandwich-style notched tensile specimen model were about $0.021 \mathrm{~mm}$ and about 118.94MPa. Lastly, the deformation and the stress for stainless steel-aluminum core sandwich-style notched tensile specimen model were about $0.024 \mathrm{~mm}$ and about $136.78 \mathrm{MPa}$. This study is thus concerned with tensile strength as shown in CFRP among other composite materials, which draws attention for its excellent durability and lightness, and stainless steel and aluminum, which are widely used metals, and is designed to acquire data with a view for future studies on the fracture and durability of heterogeneous and various composite materials. The data obtained from the studies can be utilized as the basic data for studies on the composite materials like CFRP and other various materials.

Table 3: Comparison Analysis Results of Specimen Models

\begin{tabular}{llll}
\hline & $\begin{array}{l}\text { Maximum defor- } \\
\text { mation }(\mathrm{mm})\end{array}$ & $\begin{array}{l}\text { Maximum equiva- } \\
\text { lent stress (MPa) }\end{array}$ & $\begin{array}{l}\text { Maximum } \\
\text { Load (N) }\end{array}$ \\
\hline $\begin{array}{l}\text { CFRP-Stainless } \\
\text { CFRP-aluminum }\end{array}$ & 0.0136 & 77.31 & 65,000 \\
$\begin{array}{l}\text { Aluminum- } \\
\text { stainless steel }\end{array}$ & 0.0168 & 95.15 & 80,000 \\
$\begin{array}{l}\text { Stainless steel- } \\
\text { Aluminum }\end{array}$ & 0.021 & 118.94 & 100,000 \\
\hline
\end{tabular}

\section{Conclusions}

In this study, we designed sandwich-style notched tensile specimen models that applied to the properties of CFRP, stainless steel, and aluminum and performed a simulation analysis, reaching the following conclusions.

1) By designing the sandwich-style notched tensile specimen models of the same specifications and performing a simulation analysis, we were able to verify the tensile strength and durability of the specimen models for the different materials.

2) CFRP-stainless steel core sandwich-style notched tensile specimen model showed the maximum load of about $65,000 \mathrm{~N}$ when the displacement reached about $7 \mathrm{~mm}$, and CFRP-aluminum core sandwich-style notched tensile specimen model showed the maximum load of about $80,000 \mathrm{~N}$ when the displacement reached about $6 \mathrm{~mm}$. Aluminumstainless steel core sandwich-style notched tensile specimen model showed the maximum load of about $100,000 \mathrm{~N}$ when the displacement reached about $5 \mathrm{~mm}$, and stainless steelaluminum core sandwich-style notched tensile specimen model registered the maximum load of about $115,000 \mathrm{~N}$ when the displacement reached about $5 \mathrm{~mm}$. Meanwhile, the deformation and the stress for CFRP-stainless steel core sandwich-style notched tensile specimen model were about $0.0136 \mathrm{~mm}$ and about $77.31 \mathrm{MPa}$ and the deformation and the stress for CFRP-aluminum core sandwich-style notched tensile specimen model were about $0.0168 \mathrm{~mm}$ and about 95.15MPa, the deformation and the stress for aluminumstainless steel core sandwich-style notched tensile specimen model were about $0.021 \mathrm{~mm}$ and about $118.94 \mathrm{MPa}$, while the deformation and the stress for Stainless steel-aluminum core sandwich-style notched tensile specimen model were about $0.024 \mathrm{~mm}$ and about $136.78 \mathrm{MPa}$,

3) The analysis showed that unlike the specimen modes for the ordinary metals, those specimen models with the properties of the composite material of CFRP first showed the maximum load instead of breaking immediately due to the fibers in CFRP, before they resisted the displacement in response to the alternately increasing and decreasing load until it fractured. To be specific, we saw that the CFRP specimen models had the more excellent tensile strength and durability.

4) This study is thus concerned with tensile strength as shown in CFRP among other composite materials, which draws attention for its excellent durability and lightness, and stainless steel and aluminum, which are widely used metals, and is designed to acquire data with a view to future studies on the fracture and durability of heterogeneous and various composite materials. The data obtained from the studies can be utilized as the basic data for studies on the composite materials like CFRP and other various materials.

\section{Acknowledgement}

This research was supported by Basic Science Research Program through the National Research Foundation of Korea (NRF) funded by the Ministry of Education, Science and Technology (2015R1D1A1A01057607).

\section{References}

[1] ALiu, Y., Dai, F., Xu, N., Zhao, T., \&Feng, P. (2018).Experimental and numerical investigation on the tensile fatigue properties of rocks using the cyclic flattened Brazilian disc method, Soil Dynamics and Earthquake Engineering, 105, 68-82.

[2] Kumar, V. V., \& Saride, S. (2018). Evaluation of cracking resistance potential of geosynthetic reinforced asphalt overlays using direct tensile strength test, Construction and Building Materials, 162, 37-47.

[3] Mirsayar, M. M. (2018).On fracture analysis of dental restorative materials under combined tensile-shear loading, Theoretical and Applied Fracture Mechanics, 93, 170-176.

[4] Nguyen, K., Kim, H. C., Shin, H., Yoo, Y.,\& Kim, B. (2017).Numerical investigation into the stress wave transmitting characteristics of threads in the split Hopkinson tensile bar test, International Journal of Impact Engineering, 109, 253-263.

[5] Lu, Z., \&Xian, G. (2017).Combined effects of sustained tensile loading and elevated temperatures on the mechanical properties of pultruded BFRP plates, Construction and Building Materials, 150, 310-320

[6] Du, Y., Zhang, M., Zhou, F.,\& Zhu, D. (2017).Experimental study on basalt textile reinforced concrete under uniaxial tensile loading, Construction and Building Materials, 138, 88-100.

[7] Komori, K. (2017).Predicting ductile fracture in ferrous materials during tensile tests using an ellipsoidal void model, Mechanics of Materials, 113, 24-43.

[8] Ohguchi, K.I., \& Kurosawa, K. (2016).An Evaluation Method for Tensile Characteristics of $\mathrm{Cu} / \mathrm{Sn}$ IMCs Using Miniature Composite Solder Specimen, Journal of electronic materials, 45(6), 3183-3191.

[9] Ma, Z., Zhao, H., Lu, S., Li, H.,\&Liu, C. (2016). Method for determining the true stress of cross-shaped specimens subjected to biaxial tensile loads, Instruments and Experimental Techniques, 59(2), 287-293.

[10] Komori, K. (2016).Predicting ductile fracture in pure metals and alloys using notched tensile specimens by an ellipsoidal void model Engineering Fracture Mechanics, 151, 51-69.

[11] Kato, T., Ohata, M., Nogami, S.,\&Tanigawa, H (2016).Evaluation of impacts of stress triaxiality on plastic deformability of RAFM steel using various types of tensile specimen, $F u$ sion Engineering and Design, 109-111, 1631-1636.

[12] Sui, F., Sandström, R. (2016).Slow strain rate tensile tests on notched specimens of copper, Materials Science and Engineering: A, 663, 108-115.

[13] Bruchhausen, M., Lapetite, J., Ripplinger, S., \&Austin, T. (2016).Small punch tensile/fracture test data and 3D specimen surface data on Grade 91 ferritic/martensitic steel from cryogenic to room temperature, Data in Brief, 9, 245-251.

[14] Lee, D. (2016).Fracture mechanical model for tensile strength of particle reinforced elastomeric composites, Mechanics of Materials, $102,54-60$ 